\title{
Mortality from lung cancer and population risk attributable to asbestos in an asbestos cement manufacturing town in Italy
}

\author{
Corrado Magnani, Massimo Leporati
}

\begin{abstract}
Objective-To estimate mortality from lung cancer and the risk attributable to asbestos separately for asbestos cement workers and for the general (nonoccupationally exposed) population in the town of Casale Monferrato, where the largest Italian asbestos cement factory had been in operation in 1907-86. According to cancer registry data, in the same town the incidence of malignant mesothelioma in the general population is about 10 times higher than in comparable Italian provinces.
\end{abstract}

Method-Decedents from lung cancer in 1989-95 were nominally identified in the list of decedents kept at the Local Health Authority of Casale Monferrato. Workers in the asbestos cement factory have been identified with a search in the nominal list of workers and the same was done for the wives of asbestos cement workers. These lists have already been used in cohort studies. Sensitivity and specificity of the linkage procedure with occupational activity in asbestos cement production have been evaluated in a previous study. Population at risk was estimated on the basis of official figures and on the results of the cohort study of asbestos cement workers. Results-227 deaths from lung cancer were included (184 men and 43 women). Among the asbestos cement workers mortalities were $234.0 \times 100000$ person-years among men and 35.5 among women. Corresponding figures in the general (nonoccupationally exposed) population in Casale Monferrato were 80.6 and 18.7. The rates in the general population were not higher than in the rest of the region. Attributable risk (AR) among the asbestos cement workers (and wives) is $67.5 \%(95 \%$ confidence interval $(95 \%$ CI) 56.8 to 78.2$)$ for men and $51.3 \%(95 \%$ CI 14.9 to 87.8$)$ among women. Population AR to occupational or paraoccupational exposure in the asbestos cement production is $18.3 \%(95 \%$ CI 11.1 to 25.6 ) among men and $10.1 \%$ (95\% CI 0 to 24.6) among women.

Conclusion-This work did not show an increase in mortality from lung cancer for the population not exposed occupationally, but a large excess was found among men and women occupationally exposed in asbestos cement production. The total burden of lung cancer due to occupational exposure to asbestos may be underesti- mated, as only occupational exposure in asbestos cement production was taken into consideration. Nevertheless even a single factory can be responsible for a considerable proportion of deaths from lung cancer in a population.

(Occup Environ Med 1998;55:111-114)

Keywords: asbestos; lung neoplasm; population attributable risk

Only a few studies are available on the occurrence of lung cancer in communities close to asbestos factories or mines and none considered specifically the manufacture of asbestos cement. Hammond et al did not find differences in mortality from lung cancer between residents in a town with an amosite asbestos factory and residents in another town, after excluding the amosite workers.

Geographical studies on mortality from lung cancer have been conducted in the neighbourhood of asbestos mines by Siemiatycki in Canada $^{2}$ and by Botha et $a l^{3}$ in South Africa. Both studies show a modest increase in mortality but occupationally exposed subjects were not excluded. De Vos $e t a l^{4}$ estimated the attributable risk from asbestos to be $5.7 \%$ in the Glasgow area, where asbestos has been largely used in the shipbuilding industries, with incidence of mesothelioma as an indicator of exposure. The method used by De Vos et al is simpler than a population based case-control study, but the exposure estimate is indirect and it is not possible to provide a separate estimate for subjects not occupationally exposed.

We applied, in Casale Monferrato, a more direct approach for estimating the weight of occupational exposure to asbestos in mortality from lung cancer and we took advantage of the unique condition determined by a large asbestos cement factory in a small (40 000 inhabitants) non-industrial town without other asbestos industries. The factory (owned by Eternit) was active in 1907-85 and was close to residential neighbourhoods. Both chrysotile and crocidolite were used: in 1980 crocidolite accounted for $10 \%$ of the 15000 tonnes of asbestos used in the factory. No figures are available for the previous years. ${ }^{5}$ This paper estimates mortality from lung cancer for asbestos cement workers and for the general (non-occupationally exposed) population separately and computes population attributable risk per cent (PARP) for asbestos cement production. 
Table 1 Distribution of the number of person-years in 1989-95 by age class, sex, and exposure in the production of asbestos cement or as the wife of an asbestos cement worker (see text)

\begin{tabular}{|c|c|c|c|c|}
\hline \multirow[b]{2}{*}{ Person-years } & \multicolumn{2}{|l|}{ Men } & \multicolumn{2}{|l|}{ Women } \\
\hline & Exposed & Non-exposed & Exposed & Non-exposed \\
\hline $0-4$ & 0.0 & 4875.0 & 0.0 & 4347.0 \\
\hline $5-9$ & 0.0 & 4830.0 & 0.0 & 4273.0 \\
\hline $10-4$ & 0.0 & 5477.0 & 0.0 & 5299.0 \\
\hline $15-9$ & 0.0 & 7308.0 & 0.0 & 7038.0 \\
\hline $20-4$ & 0.0 & 9079.0 & 1.6 & 8594.4 \\
\hline $25-9$ & 14.7 & 10583.3 & 71.1 & 10151.9 \\
\hline $30-4$ & 164.4 & 9834.6 & 264.7 & 9766.3 \\
\hline $35-9$ & 332.1 & 8959.9 & 254.0 & 8972.0 \\
\hline $40-4$ & 300.2 & 8753.8 & 313.9 & 9027.1 \\
\hline $45-9$ & 323.5 & 8359.5 & 719.9 & 8355.1 \\
\hline $50-4$ & 816.2 & 7824.8 & 1274.5 & 8213.5 \\
\hline $55-9$ & 1268.6 & 8093.4 & 1695.0 & 8143.0 \\
\hline $60-4$ & 1392.4 & 7360.6 & 1826.5 & 8554.5 \\
\hline $70-4$ & 1086.9 & 6655.1 & 1436.0 & 8588.0 \\
\hline $75-9$ & 567.1 & 5004.9 & 980.1 & 7202.9 \\
\hline $80-4$ & 325.1 & 3366.9 & 706.6 & 5572.4 \\
\hline$\geqslant 85$ & 318.3 & 4388.7 & 758.9 & 10178.1 \\
\hline Total & 6909.5 & 120763.5 & 10302.8 & 131580.2 \\
\hline
\end{tabular}

Material and methods

The study is based on the nominal list of residents in Casale Monferrato dying from lung neoplasms from 1 January 1989 to 31 December 1995 abstracted by us from official records. The list also includes the people who died in other towns. No information on occupation is available on those records.

This list was linked with the lists of workers in the asbestos cement factory and of their wives, to identify the people occupationally or paraoccupationally exposed to asbestos in asbestos cement production. ${ }^{56}$ The linkage procedure had been developed and tested by us in a previous study on malignant mesothelioma in the same area. ${ }^{7}$ For simplicity the subjects (decedents and population at risk) are defined as exposed if they ever worked in the asbestos cement factory or were married to a worker in the factory and non-exposed otherwise.

The population at risk was estimated from different sources. The total population was estimated in 1991 (national census) and in 1994 (figures provided by the Town Office). The population resident in the city of Casale Monferrato is stable: the total population in 1991 accounted for 38962 and in 1994 for 38 050 people. The rates for periods $1989-91$ and 1992-95 were computed with the 1991 and 1994 populations, respectively. The size, age, and sex distribution of the exposed (occupationally or paraoccupationally) population was estimated from the last follow up of the cohorts of asbestos cement workers ${ }^{5}$ and of their wives, ${ }^{6}$ with consideration for the expected mortality

Table 2 Number of deaths and mortalities from lung cancer (per 100000 person-years) in Casale Monferrato in 1989-95 by sex and exposure in the production of asbestos cement or as the wife of an asbestos cement worker (see text)

\begin{tabular}{lllll}
\hline & Total & Exposed & Non-exposed & Piedmont \\
\hline Men: & & & & \\
n & 184 & 50 & 134 & \\
Rate & 98.4 & 234.0 & 80.6 & 80.6 \\
95\% CI & 83.5 to 113.2 & 165.3 to 302.6 & 66.4 to 94.9 & \\
Women: & & & & \\
n & 43 & 9 & 34 & 13.3 \\
Rate & 21.0 & 35.5 & 18.7 & \\
$95 \%$ CI & 14.5 to 27.6 & 11.5 to 59.6 & 12.1 to 25.3 & \\
\hline
\end{tabular}

${ }^{\star}$ Men ever engaged in asbestos cement production, and women ever engaged in asbestos cement production or married to an asbestos cement worker. after the end of follow up and of the aging of cohort subjects. The non-exposed population was estimated as the difference between the total and exposed population. Table 1 shows the distribution of person-years by age, sex, and exposure.

Rates were directly standardised on the 1981 Italian population and their 95\% confidence intervals (95\% CIs) were computed according to Smith. ${ }^{8}$ The relative risk (RR) was computed according to Mantel-Haenszel $\mathrm{RR}_{\mathrm{MH}}$, following Greenland, ${ }^{9}$ as were the attributable risk (AR), its variance, and the $95 \% \mathrm{CI}$. The $\mathrm{AR}$ and PARP are expressed as percentages.

\section{Results}

In 1989-95 227 deaths among the Casale Monferrato residents were attributed to lung cancer: 184 in men and 43 in women. Mortalities ( $\times 100000$ person-years, age adjusted) were respectively 98.4 and 21.0.

Table 2 shows the number of cases and the mortality by sex and exposure and the mortality in Piedmont in 1989-91. Nonexposed men (those never employed in the local asbestos cement industry) had the same mortality as the general population in Piedmont. Non-exposed women had a mortality higher than in Piedmont (18.7 v 13.3) but the difference was not significant.

From these figures we estimate that $5.6 \%$ of men living in Casale in 1989-95 had been occupationally exposed in the production of asbestos cement. The $\mathrm{RR}_{\mathrm{MH}}$ (exposed $v$ nonexposed) was 3.07 (95\% CI 2.21 to 4.28 ) and the AR among the exposed was $67.5 \%(95 \%$ CI 56.8 to 78.2 ). In the same period $7.3 \%$ of women had been either occupationally exposed in the same industry or paraoccupationally exposed through marriage with an asbestos cement worker. There were too few deaths from lung neoplasms among women for separate analyses by occupational and paraoccupational exposures. The $\mathrm{RR}_{\mathrm{MH}}$ was 2.05 (95\% CI 0.98 to 4.31 ) and the AR among exposed women was $47.0 \%$ (95\% CI 14.9 to 87.8).

In the general population of Casale Monferrato PARP for occupational or paraoccupational exposure to asbestos from the production of asbestos cement was $18.3 \%$ (95\% CI 11.1 to 25.6 ) among men and $10.1 \%$ (95\% CI 0 to 24.6) among women.

No significant variation was found by analysing mortality by period. Mortalities among exposed men were 258.8 in 1989-91 and 233.8 in 1992-95; corresponding figures in women were 41.6 and 27.8. Among non-exposed men rates were 78.7 in 1989-91 and 84.7 in 1992-95, and in women 20.4 and 18.2. In both the exposed and non-exposed categories variation was non-systematic.

Table 3 shows mortalities by age in Casale Monferrato and in Piedmont by exposure. If we excluded the age classes $<50$, in which there are too few cases, the ratio between mortalities among exposed and non-exposed people was always in the range $2.5-3.5$ in men and 1.8-2.8 in women. 
Table 3 Number of deaths from lung cancer and corresponding mortalities (per 100000 person-years) in Casale Monferrato 1989-95 by age class, sex, and exposure in the production of asbestos cement or as the wife of an asbestos cement worker (see text)

\begin{tabular}{|c|c|c|c|c|c|c|}
\hline \multirow[b]{2}{*}{ Age } & \multicolumn{2}{|c|}{ Exposed ${ }^{\star}$} & \multicolumn{2}{|c|}{ Non-exposed } & \multicolumn{2}{|c|}{ Piedmont 1989-91 } \\
\hline & $n$ & Rate & $n$ & Rate & $n$ & Rate \\
\hline \multicolumn{7}{|l|}{ Men: } \\
\hline$<40$ & 0 & 0.0 & 1 & 1.6 & 30 & 3.3 \\
\hline $40-9$ & 0 & 0.0 & 6 & 35.1 & 264 & 29.3 \\
\hline $50-9$ & 7 & 335.8 & 2 & 131.9 & 1162 & 129.5 \\
\hline $60-9$ & 22 & 887.4 & 38 & 271.1 & 2480 & 348.9 \\
\hline $70-9$ & 15 & 1681.2 & 45 & 537.5 & 1809 & 475.3 \\
\hline$\geqslant 80$ & 6 & 1885.1 & 23 & 524.1 & 793 & 462.8 \\
\hline \multicolumn{7}{|l|}{ Women: } \\
\hline$<40$ & 0 & - & 0 & - & 6 & 0.8 \\
\hline $40-9$ & 0 & - & 2 & 11.5 & 48 & 5.3 \\
\hline $50-9$ & 2 & 67.4 & 4 & 24.5 & 154 & 16.6 \\
\hline $60-9$ & 3 & 92.0 & 9 & 52.5 & 203 & 35.9 \\
\hline $70-9$ & 3 & 177.9 & 12 & 93.3 & 398 & 69.3 \\
\hline$\geqslant 80$ & 1 & 131.8 & 7 & 68.8 & 289 & 72.3 \\
\hline
\end{tabular}

${ }^{\star}$ Men ever engaged in asbestos cement production, and women ever engaged in asbestos cement production or married to an asbestos cement worker.

\section{Discussion}

The study aims at evaluating the contribution of occupational exposure and related paraoccupational exposure from asbestos cement production to mortality from lung cancer in the town of Casale Monferrato, where the largest Italian asbestos cement factory was located.

In previous reports of Casale Monferrato we showed a large increase in the incidence of mesothelioma among the general population not occupationally exposed. ${ }^{7}$ In this study the same methods were adopted for separating deaths from lung cancer by occupational activity in the asbestos cement factory. This procedure is meaningful as no other major industrial activity using asbestos was located in the town or in its surroundings. ${ }^{7}$

The file of the mesothelioma registry of Piedmont $^{7}$ was examined to identify cases of mesothelioma misdiagnosed as lung neoplasms. Four such cases were found (two men and two women), none of whom had a record of occupational exposure in the asbestos cement industry. In three cases the diagnosis of mesothelioma was dubious and based on cytological diagnosis only. These four subjects were retained as the study was based on mortality records.

To reduce possible errors in estimating the population size and its age structure we adopted a procedure based on the most accurate available data. The size of the exposed population was based on the follow up of the cohort studies conducted in the area, the size of the total population was estimated according to official estimates, and that of the non-exposed population was the difference between the two.

The male subjects who did not work in asbestos cement production (non-exposed) did not have different mortalities from elsewhere in the Piedmont region. A small increase was found among women, which did not reach significance.

Our procedure for identifying subjects with occupational exposure to asbestos and for estimating the corresponding population size was limited to a specific activity (asbestos cement production) and did not take into account other sources of exposure. The use of asbestos cement products was common in Casale but our data cannot be used to identify workers exposed in other occupations - such as construction workers. At the 1981 census, 932 men were active in construction and related industries (this figure includes workers active in Casale but living elsewhere). If this activity carries an increased risk for lung cancer, the inclusion of these workers slightly overestimates mortalities of non-exposed people. However, we should take into consideration that such exposures are included in the reference rates for Piedmont and therefore the error in the comparison is minimal.

The present results about subjects formerly engaged in the asbestos cement factory show a good agreement with our mortality follow up study. ${ }^{5}$ Among men, the standardised mortality ratio (SMR) found in that study for the period 1985-92 was 2.32 , based on 65 cases. In the present study, in 1989-95 the ratio between the mortalities of asbestos cement workers and of the population of Piedmont was 2.90, based on 50 cases.

The contribution of cigarette smoking could not be evaluated as individual information on smoking habits was not available.

A few studies have been conducted on the proportion of lung cancers attributable to asbestos in the general population and a summary has been presented by Albin et $a l^{10}$ who found that most studies estimated PARP at $10 \%-20 \%$ with a range between $19 \%$ and $53 \%$. The highest PARPs were found in areas with chemical and shipbuilding industries, ${ }^{11}$ harbours and shipyards, ${ }^{12}$ and close to an amosite mine. ${ }^{13}$ In the present study the AR among exposed men was $67.5 \%$ and for women it was $51.3 \%$ whereas in the general population (not occupationally exposed) PARP it was $18.3 \%$ among men and $10.1 \%$ among women.

Measures of environmental asbestos exposure in the town of Casale Monferrato are available only for recent years and may underestimate exposure when the asbestos cement factory was fully active. Marconi in $1984^{14}$ found asbestos fibres $>5 \mu \mathrm{m}$ in concentrations of between 11 asbestos fibres/l close to the plant and 1 asbestos fibre/ 1 in the city area farthest away from the plant. Non-chrysotile asbestos fibres ranged between $15 \%$ and $30 \%$ of total fibres. The Local Health Authority in 1991 measured annual average concentration of asbestos fibres $>5 \mu \mathrm{m}$ to be below one asbestos fibre/l, this threshold being exceeded in $12 \%$ of samples. Between $20 \%$ and $50 \%$ of asbestos fibres were amphiboles (internal report, Local Health Authority of Casale Monferrato). In 1991 Chiappino et al ${ }^{15}$ measured concentration of asbestos fibres (length $>5 \mu \mathrm{m}$ and diameter $0.3 \mu \mathrm{m}$ ) in Casale Monferrato to be in the range 2.2-7.4 asbestos fibres/1 in residential areas of the city with amphiboles representing over $50 \%$ of the fibres. The difference among these studies could be partly due to the different methods used for sampling and analyses.

Results from the present work did not show an increase in mortality from lung cancer for the population that has not been occupationally 
exposed whereas a large excess was found among men and women occupationally exposed in the asbestos cement production. Our study may have underestimated the total burden of lung cancer due to occupational exposure to asbestos, as it did not take into consideration exposure other than in the production of asbestos cement. Nevertheless we showed that even a single factory can be responsible for a considerable proportion of the deaths from lung cancer in a population. At the same time this study did not find an increase in lung cancer deaths in Casale Monferrato associated with environmental exposure to asbestos, contrary to what was found in the same town for mesothelioma.

This study was conducted thanks to contributions from the EEC-Europe Against Cancer Programme and from the Italian Association for Cancer Research (AIRC). We thank D Donatella Schiavo who contributed to data collection, Dr Giorgio Topi from the town office of Casale Monferrato who provided the population figures, Dr Alberto Salvan, and D Roberto Zanetti for their comments, and Mrs Daniela Mezzomo and Rita Giacometti for the careful typing.

1 Hammond EC, Garfinkel L, Selikoff IJ, et al. Mortality experience of residents in the neighbourhood of an asbestos factory. Ann N Y Acad Sci 1979;330:417-422.

2 Siemiatycki J. Health effects on the general population mortality in the general population in asbestos mining areas. In: Proceedings of the World Symposium on Asbestos. Montreal: Canadian Asbestos Information Centre, 1983: 337-48.

3 Botha JL, Irwig LM, Strebel PB. Excess mortality from stomach cancer, lung cancer and asbestosis and/or mesothelioma in crocidolite mining districts in South Africa. Am F Epidemiol 1986;123:30-40.

4 De Vos Irvine H, Lamont DW, Hole DJ, et al. Asbestos and lung cancer in Glasgow and the west of Scotland. BMF 1993;306:1503-6.

5 Magnani $\mathrm{C}$, Terracini $\mathrm{B}$, Ivaldi $\mathrm{C}$, et al. Mortalità per tumori altre cause tra i lavoratori del cemento-amianto a Casale Monferrato. Med Lav 1996;87:133-46.

6 Magnani C, Terracini B, Ivaldi C, et al. A cohort study on mortality among wives of workers in the asbestos-cement industry in Casale Monferrato, Italy. $\mathrm{Br} f$ Ind Med industry in Casale

7 Magnani C, Terracini B, Ivaldi C, et al. Pleural malignant mesothelioma and non-occupational environmental exposure to asbestos in Casale Monferrato, Italy. Occup Environ Med 1995;52:362-7.

8 Smith PG. Comparison between registries: age standardised rates. In: Parkin DM, Muir CS, Whelan SL, et al, eds. Cancer incidence in five continents. Vol VI. Lyon: IARC 1992. (IARC Sci Publ No 120.)

9 Greenland S. Variance estimator for attributable fraction estimates consistent in both large strata and sparse data. Stat Med 1987;6:701-8.

10 Albin M, Shefer I, Magnani C, et al. Asbestos and cancer. Tenth International Symposium: epidemiology in occupational health. Como, 20-24 September 1994. Med Lav 1994;86:259-62.

11 Kjuus H, Langard S, Skjaervern R. A case referent study of ung cancer, occupational esposure and smoking. Scand $\mathcal{F}$ Work Environ Health 1986;12:210-5.

12 Bovenzi M, Stanta G, Antiga G, et al. Occupational exposure and lung cancer risk in a coastal area of northeastern Italy. Int Arch Occup Environ Health 1993;65: 35-41.

13 Parolari G, Merler E, Ricci P. Mortalità per tumore attribuibile all'esposizione lavorativa ad amianto amosite in una bile all'esposizione lavorativa ad amianto
comunità. Epidemiol Prev 1988;37:32-7.

14 Marconi A. Airborne mineral fibre concentrations in an urban area near an asbestos-cement plant. IARC Sci Publ 1989;90:336-46.

15 Chiappino G, Sebastien P, Todaro A. L'inquinamento atmosferico da amianto nell'ambiente urbano: Milano, Casale Monferrato, Brescia, Ancona, Bologna, Firenze. Med Lav 1991;82:424-38. 